\title{
Performances of the Italian Seismic Network, 1985-2002: the hidden thing
}

\author{
Alessandro Marchetti, Salvatore Barba, Luigi Cucci and Mario Pirro \\ Istituto Nazionale di Geofisica e Vulcanologia, Roma, Italy
}

\begin{abstract}
Seismic data users and people managing a seismic network take a great interest in the potentiality of the data, with the difference that the former look at stability, the latter at improvements. This work measures the performances of the Italian Telemetered Seismic Network in the years 1985-2002 by defining basic significant parameters and studying their evolution during those years. Then, we deal with the geological methods used to characterise or to plan seismic station deployments in a few cases. Last, we define the gain of the network as the percentage of well-located earthquakes with respect to the total recorded earthquakes. By analysing the distribution of non-located («missed») earthquakes, we suggest possible actions to take to increase the gain. Results show that completeness magnitude is 2.4 in the average over the analysed period, and it can be as low as 2.2 when we consider non-located earthquakes as well. Parameters such as the minimum recording distance and the RMS of the location decrease with time, reflecting improvements in the location quality. Methods for geologic and seismological characterisation of a possible station site also proved effective. Finally, we represent the number of missed earthquakes at each station, showing that nine stations control more than $50 \%$ of all missed earthquakes, and suggesting areas in Italy where the network might easily be improved.
\end{abstract}

Key words Italy - seismic networks - seismic dataearthquake location

\section{Introduction}

Seismic data analysis at the Istituto Nazionale di Geofisica e Vulcanologia (INGV) begins as soon as the data are acquired, going from automatic processing within a few seconds, for very rapid earthquake response, to analysts review within a few days or weeks, for earthquake catalogues and quality control. Immediate earthquake information for Italy and surrounding areas includes location, magnitude, expected damage, and, for larger events, source description and historical analysis. IN-

Mailing address: Dr. Alessandro Marchetti, Istituto Nazionale di Geofisica e Vulcanologia, Via di Vigna Murata 605, 00143 Roma, Italy; e-mail: alessandro.marchetti@ingv.it
GV then reports earthquake information to public and private agencies.

On a daily basis, analysts revise the previously reported events and read new ones, picking phases, locating the events, and reporting magnitude. In addition to local and regional earthquake location, analysts read teleseismic phases. All this work converges into standard location reports commonly called «seismic bulletins».

Over the past 20 years, the INGV has invested in the development of the software and hardware needed for automated, real-time earthquake analysis. Specifically, in the very latest years the station density, the instrumentation quality, and the software capabilities strongly increased; this resulted in greater quality, quantity and immediacy of earthquake locations. Analogue transmission and chemical paper recordings yielded to digital connections and broadband seismometers, improving the accuracy of readings, whereas a greater station density allowed recognizing earthquake sources with more details. 
The long-lasting dataset allows changes in seismicity parameters with time to be studied, e.g., $b$-value, moment release rate, and clustering properties, and the amount of new analyses strictly follows the increase of data quality. The knowledge of human-induced changes thus assumes a great importance in planning the analyses and evaluating the results.

Parallel to these improvements in software and instrumentation, in the past 10-12 years great efforts were made to come up to good standards in the process of site selection through detailed geological surveys. This process is very important, because accounting for the geology of a potential site can improve the station efficiency and maximize the advantages of the technological improvements.

This work analyses the temporal changes in quantities that depend on the ongoing transformations, e.g., minimum hypocentral distance, completeness magnitude, and RMS. In addition, we also illustrate how the criteria of installationsite selection changed with time, showing samples of interesting geological settings found during routine site investigations. In order to highlight the improvements of the network, like station density and recording quality, we relocate the 1985-2002 earthquakes adopting, over the whole dataset, the same criteria used to relocate the official INGV seismic bulletin during the year 2004. Such information gain interest because of the widespread availability of data due to pagers, e-mail, and the www.

\section{Data and instrumentation}

\subsection{The Italian Telemetered Seismic Network}

The Italian Telemetered Seismic Network (ITSN) has been continuously operating shortperiod instrumentation since the year 1980. Since then, there have been two major development phases. The first occurred during the years 1981-1984: the network moved to digital acquisition (Taccetti and Mele, 1989; Boschi et al., 1990), and the station density strongly increased (De Simoni, 1987). The second has been occurring since the year 2002: transmission changed from analogue to digital (Badiali

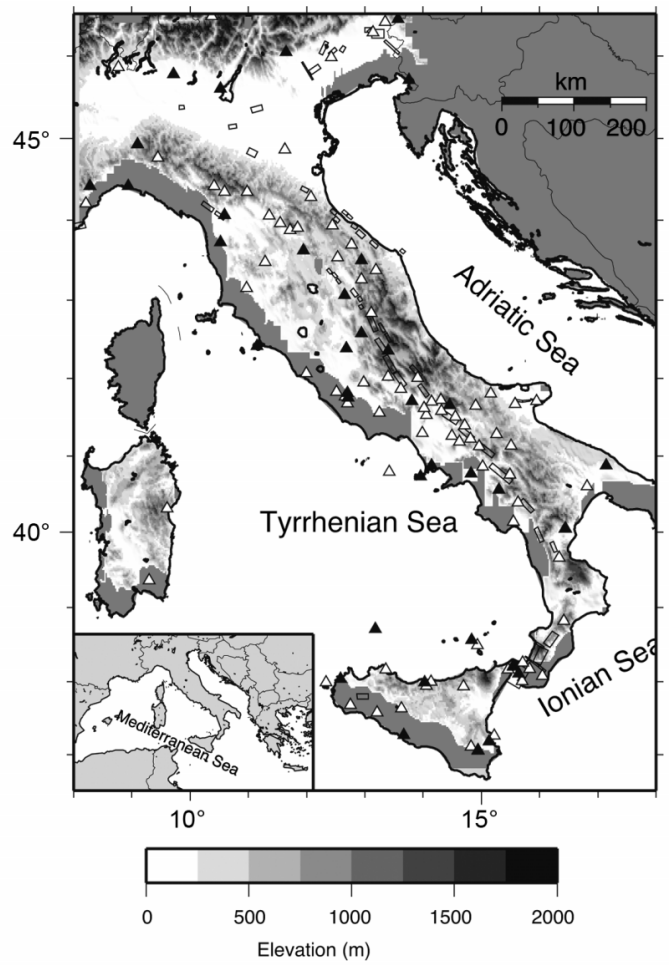

Fig. 1. The Italian Telemetered Seismic Network at the beginning of year 1985 (black triangles) and at the end of year 2002 (black and white triangles). Boxes represent potential seismogenic sources for $M>5.5$ earthquakes according to Valensise and Pantosti (2001).

and Mele, 2000), including satellite, and new kind of instruments have been deployed, mostly broadband. Figure 1 shows the location of seismic stations in 1984 and in 2002, in between the two largest development phases.

\subsection{The dataset}

We dealt with all the local and regional data recorded by the ITSN (Barba et al., 1995a,b) from 1 January 1985 to 31 August 2002 (hereinafter 1985-2002). "All data» means that we did not select any subset a priori. More specifically, we used 1) earthquakes that have been located, 2) earthquakes that had not enough da- 
ta to give a reliable location, and 3) sparse readings where the $S$ - $P$ time and magnitude are reliable. In all, the specified data set consists of 113199 seismic events, of which 45191 have been reliably located, whereas the remaining 68008 are either poorly located events or isolated single station readings. Among these latter events, the majority (66698) have reliable $S-P$ time reading at the closest station. All these data get together into the public seismic bulletins, available for download at http://www.ingv.it/ or by ftp at ftp://ftp.ingv.it/bollet/.

\subsection{On the importance of poorly-located events}

The poorly-located and the not-locatable earthquakes («missed» earthquakes) constitute the majority of events in the dataset. We call here «poorly-located» the local events defined by the seismic analysts as such. On the other side, «not-locatable» are local earthquakes with less than seven phase readings that have both $P$ and $S$-wave readings at the closest station. When the $S$-wave is not reliable at the closest station, we completely discard the event from the dataset. Some analysis can still successfully make use of such data if the location accuracy concerns less than the magnitude completeness. For example, analysing such data might be very useful in assessing the detection capabilities of the network, or in suggesting improvements for the network geometry.

For sake of simplicity, we group together the poorly-located and the not locatable events, referring to them just as the poorly-located events. We assume as event parameters - in place of origin time and hypocentral coordinates - the arrival time of the earliest $P$-wave, the corresponding $S$ $P$ time difference, and the coordinates of the corresponding station, supposed to be closest to the hypocenter.

\subsection{Completeness magnitude}

Events in the catalogue have magnitudes between $M \sim 1.5$ and $M \sim 6.0$. Completeness magnitude is somewhat troublesome to establish because it depends on area, time, and location quality. We used the maximum of the derivative of the frequency-magnitude distribution to derive the completeness magnitude for the whole dataset. We computed the completeness magnitude for the whole catalogue (1985-2002), and for two sub-catalogues, 1985-1993 and 19972002, respectively. We found $M 2.4$ for located earthquakes, whereas poorly- or not-locatable events are complete from magnitude $M$ 2.2. We also found the completeness magnitude for located earthquakes to be $M 2.3$ in the years 19972002 only, thus reflecting the improvement in the network geometry in the latter years.

\section{Looking inside seismic bulletins}

Increasing the number of seismic stations (from 41 in the year 1984 to more than 100 in year 2002) has produced a huge quantity of low-magnitude recordings. The percentage of magnitude $M \leqq 2.5$ events increased from $20 \%$ in 1982 up to $62 \%$ in 2002. This increase suggests that ITSN data quality improved with time, but it hardly quantifies such improvement. Thus, we study here how the possible indicators of data quality, like the location RMS, the minimum and maximum hypocentral distance, and so on, changed with time. These changes were mostly due to the network geometry and to the site characteristics.

\subsection{Variation of minimum and maximum distance with time}

In order to understand how the location quality improved with time, we first assume that the error on hypocentral coordinates decreases with the distance between the earthquake and the closest station that recorded it. Here, we are neglecting the influence of the velocity model, and we are assuming that the network geometry might be considered approximately constant around the hypocenter. We selected 36942 local events with minimum hypocentral distance less than $50 \mathrm{~km}$ that occurred from January 1985 to August 2002. Then we considered monthly averages of the minimum distance and the associated standard devi- 


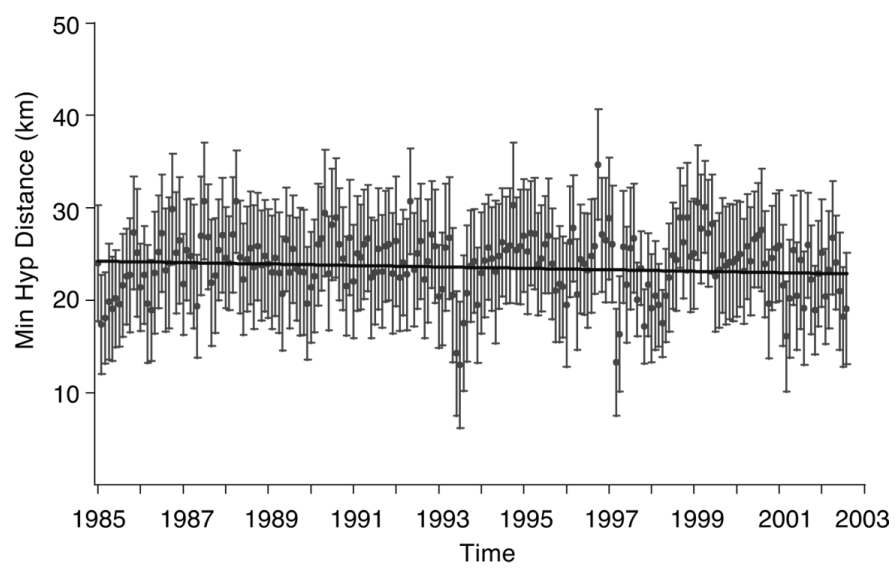

Fig. 2. Monthly averages (dots) of minimum hypocentral distance and associated standard deviation (bars) from year 1985 to August 2002. Only events with minimum distance less than $50 \mathrm{~km}$ contributed to the average. The line represents the linear fit of the minimum distance versus time.

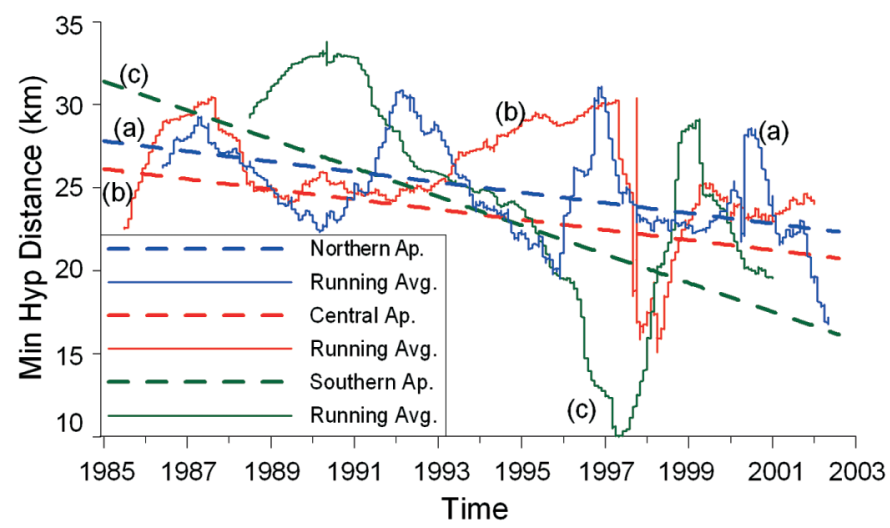

Fig. 3. Monthly averages (continuous lines) of minimum hypocentral distance like in fig. 2, but relative to (a) Northern Apennines (blue), (b) Central Apennines (red), and (c) Matese-Irpinia in Southern Apennines (green). The dashed lines represent the linear fit of the minimum distance versus time.

ation. We observe (continuous line in fig. 2) that the average minimum distance decreased $1.4 \mathrm{~km}$ from $24.3 \mathrm{~km}$ to $22.9 \mathrm{~km}$ for the entire Italian territory. Apparently, this decrement might be surprisingly small, but it is not if we consider that the ITSN also developed in areas with previous little instrumental coverage, and that coastal earthquakes contribute to the average, too. If we consider only areas that were already properly monitored, we find that the min- imum distance decreases much more. For example, the reduction is $6 \mathrm{~km}$ in the Northern Apennines (5774 events, blue line «a» in fig. 3), $5 \mathrm{~km}$ in the Central Apennines (10866 events, red line «b»), and even $15 \mathrm{~km}$ in the Matese-Irpinia, Southern Apennines (3306 events, green line $\langle\mathrm{c}\rangle)$. In this last case, the Sannio-Matese local seismic network (Di Maro and Marchetti, 1992) was incorporated into the ITSN, lowering the station spacing to $15-20 \mathrm{~km}$. Changing the 
50-km cut-off to other distances produces similar results. Therefore, we can conclude that the Network was successfully developed in the well-known hazardous areas, whereas a fair expansion was brought forth in less hazardous (or less known) areas.

As a second important issue, we want to verify how the detectability of an earthquake improves with time. There are two ways to define detectability. At short distances, we say that an earthquake is detectable if it has reliable $P$ - and $S$-wave arrival time readings at the closest station, so detectability improves if the number of low-magnitude earthquakes with both $P$ and $S$-readings increases. It actually improves, increasing the percentage of low-magnitude events from $20 \%$ to $62 \%$ as described above. The second possible definition concerns the maximum distance at which the earthquake gives reliable $P$-readings. Many factors affect the so defined detectability: the network density (only at short distances), the quality of the geological sites, the efficiency of transmission lines, the instrument sensitivity, and the reliability of the detection algorithm. We selected 40536 events, with maximum distance less than $600 \mathrm{~km}$, which occurred from January 1985 to August 2002 , and plotted monthly averages of the maximum distance. We can observe (continuous line in fig. 4) that maximum distance slightly decreases until year 1997, and it slightly increases after that year. This result suggests that the only intervening factor in 1985-2002 has been the network density, while the other characteristics have been nearly unchanged. We notice that after 2002 great changes occurred in all the other areas, as described in the Network section: digital transmission was used instead of analogue telephone lines, many broadband instruments were deployed, and digitisation from 16 bit moved to 24 bit. In addition, a strongly improved detection algorithm has been running since 2002.

\subsection{Variation of RMS with time}

The RMS of travel-time residuals is commonly used to assess the reliability of the earthquake location. This practice suffers wellknown problems, because a minimum of RMS does not automatically mean an accurate hypocentre determination (Di Giovambattista and Barba, 1997). A low RMS is easily achieved with few phase readings, whereas a good location often is not. Despite these limitations, RMS variations can indicate changes in the goodness of location, if all the other conditions are left

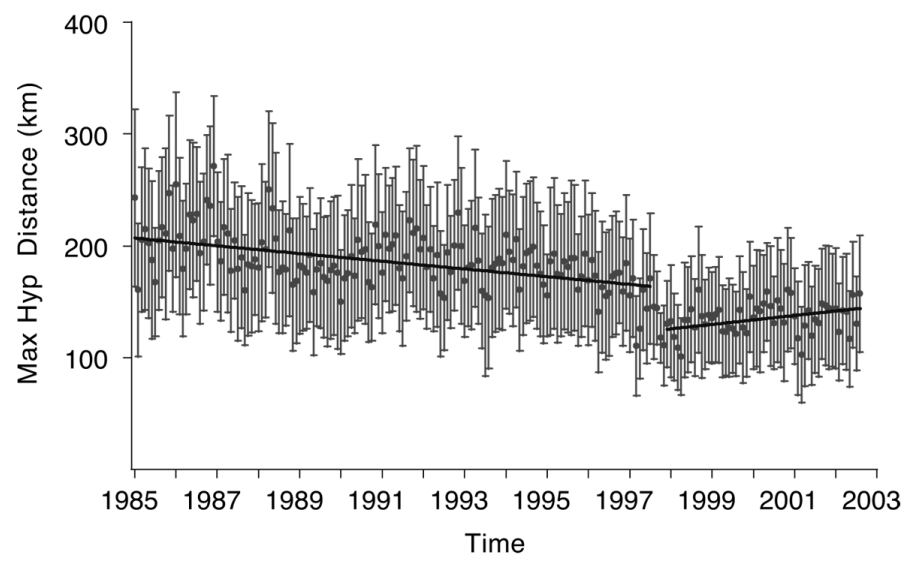

Fig. 4. Monthly averages (dots) of maximum hypocentral distance and associated standard deviation (bars) from year 1985 to August 2002. Only events with maximum distance less than $600 \mathrm{~km}$ contributed to the average. The line represents the linear fit of the maximum distance versus time. 
constant. Moreover, artefacts due to the presence of few phase readings can be easily avoided if we consider relative travel-time residuals (time per $\mathrm{km}$ ) when computing the RMS. In this section, we describe how RMS varies with time and magnitude, and how it depends on the number of $P$ - and $S$-readings actually used in locating the events.

By representing monthly averages of the RMS travel-time residuals, we can see that RMS decreases with time until year 1997 (continuous and dashed lines in fig. 5). This reduction reflects the increase in station density over the years and the consequent improvement in location accuracy both for all-magnitude events (continuous line in fig. 5) and magnitude $M \geqq 3.3$ events (dashed line). Since 1997, the RMS did not significantly decrease.

Magnitude also affects RMS, although not directly. We observe that RMS is nearly constant $(\mathrm{RMS} \approx 0.6-0.7)$ for events of magnitude $M>4$. This saturation effect depends on the upper limit in the number of phase readings. On the contrary, for lower magnitudes the RMS decreases, probably because the number of traveltimes involved in the earthquake location is smaller. This result confirms that fewer phases are likely to produce a lower RMS with possibly worse location accuracy.

\subsection{Dependence of RMS on the number of phases}

Finally, we verify how the number of $P$ - and $S$-wave arrival-time data affects the accuracy of the solution. The RMS only gives an indication of the fit of the data: the precision of the computational solution depends on various model assumptions, as well as on the number of data (Havskov et al., 2002). Therefore, we use relative travel-time residuals to asses how the accuracy of the solution depends on the number of phase readings. We compute a relative dimensionless RMS (RRMS) as

$$
\operatorname{RRMS}=\sqrt{\frac{\sum_{i=1}^{N} W_{i} \cdot\left(\frac{t_{i}-t_{0}}{t_{i}^{c}}\right)^{2}}{\sum_{i=1}^{N} W_{i}-P}}
$$

where $N$ is the number of phases used in the location, $t_{i}$ the arrival time of the $i$ th phase, $W_{i}$ the corresponding weight $\left(0 \leq W_{i} \leq 1\right), t_{0}$ the origin time, $t_{i}^{c}$ the computed travel time at the $i$ th seismic station, and $P$ the number of parameters in fit (4, or 3 if depth is fixed a priori). This parameter has less model assumptions than RMS and can better represent the accuracy of the solution. Figure 6 shows RRMS averages versus

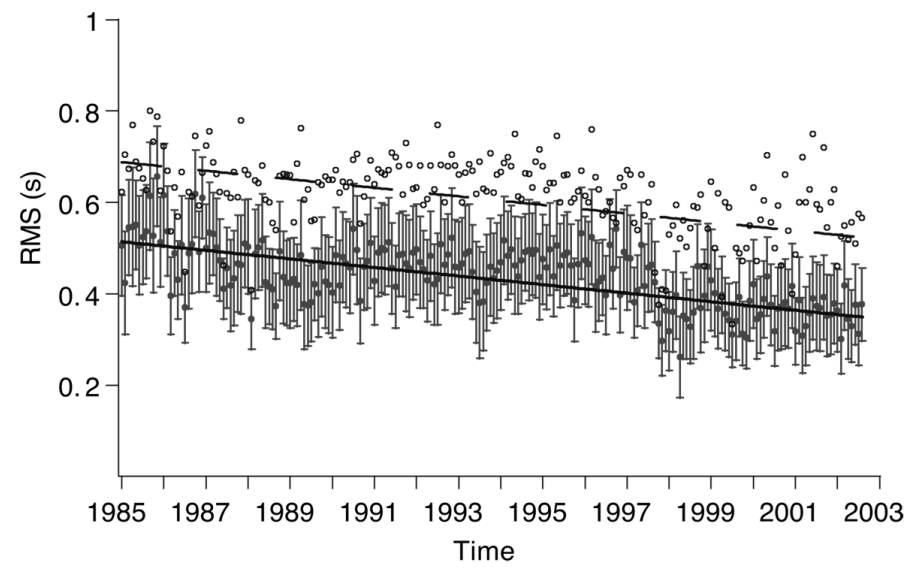

Fig. 5. Monthly averages (dots) of RMS travel time residuals and associated standard deviation (bars). The lines represent the linear fit of the RMS versus time. Open dots and dashed line pertain to magnitude $M \geqq 3.3$ events, whereas closed dots and continuous line pertain to all the events. 


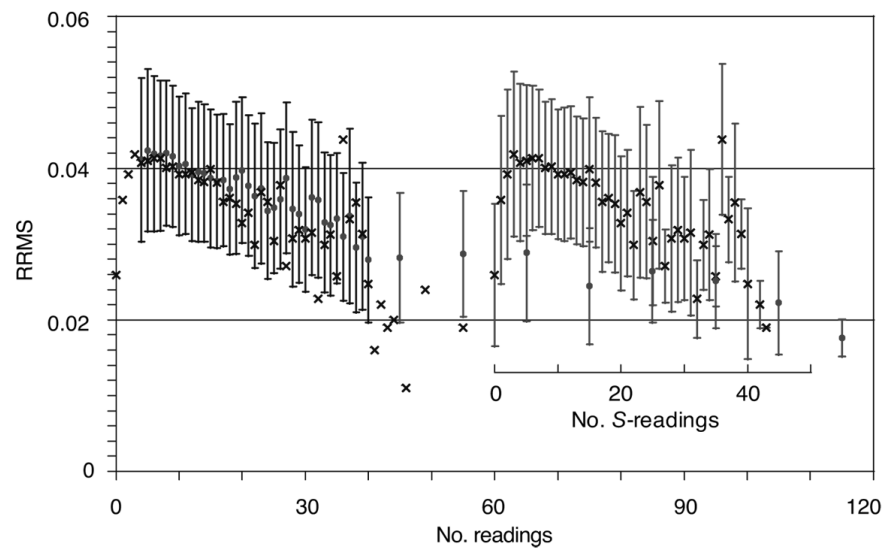

Fig. 6. Average of relative RMS (dimensionless, eq. (3.1)) of the locations and its associated standard deviation versus the number of $P$ - (dots) and $S$-wave (crosses) arrival-time data actually used in the location. Data pertaining to earthquakes with more than 40 phases have been grouped in classes of 10 phases. To avoid overlapping bars, the standard deviation bars versus the number of $S$ readings have been moved to the right side of the figure, whereas at the left side only the average values (crosses) are plotted.

the number of $P$ - and $S$-wave arrival times. We observe that the RRMS decreases when the number of phase readings increases, becoming approximately constant for more than $40 \mathrm{P}$ wave and for more than $25 S$-wave readings. Although these «average» results might vary for specific areas or at the borders of the network, we conclude that additional data do not improve the accuracy of the solution.

\section{Geological characterization of some ITSN station sites}

\subsection{Methodology for station site characterisation}

The phases of development of the ITSN observed during the past 20 years find their counterparts in the process of selection of the seismic stations. Indeed part of the improvement in the quality of the «seismological datum» has to be related to more rigorous criteria of site selection. Following an early period in which a site was normally selected by a simple test of the signal with a portable recorder and by quick morphological observations, in 1992 the INGV started a systematic geological and geomorphologic survey (Cucci and Pirro 1992, 1993) along with a detailed analysis of the seismic noise at each site (Cattaneo et al., 2002). This important work allowed to 1) significantly improve the set of data available for each surveyed station of the ITSN; 2) try to link the geology of one site to possible anomalies in the record of the seismic waves (different signal to noise ratios, capability of recording seismic events, static residuals, etc.); 3 ) identify the best possible geological conditions at sites where particular needs suggested moving the seismometer; 4) provide useful guidelines to be followed in selecting new sites.

In particular, this paper focuses on the geological characteristics of the sites and refer to Cimini et al. (1994) and Cucci et al. (1994) for the geophysical aspects of the work.

In theory, the best geological characteristics are those that supply the site with the lowest possible seismic noise. Consequently, the most frequent search is for competent rocks in low relief areas, along-depth continuity of outcrops, lack of fracturing, thin soil cover, absence of active faults and/or slope failure processes in the vicinity of the site. Nevertheless, the geo- 
logical characterisation is but one of the several features to be assessed when selecting a new site, so that often a favourable geological situation can be in conflict with other important logistic needs such as an easy access to the site or the availability of electricity and phone lines. This explains the complexity and variability of the situations that have been observed while surveying the sites of the ITSN.

Our working methodology mainly follows two steps. In order to achieve a general overview of the study area we usually collect and analyse geological, hydrogeological and geomorphic data at regional scale (order of tens of kilometres from the site). Processing these data provides 1:100000 scale maps and sections that disclose the most important geological structures. The second step of our work is the detailed geological survey of the area surrounding the site. Each outcrop is briefly described in terms of lithological characteristics, attitude, state of fracturing, and possible displacements; further observations concerning the drainage pattern, erosion features and karst phenomena complete the survey. GPS measures provide elevation and coordinates of the site. The data collected in the field are often integrated by aerial photo analyses and by the stratigraphic analysis of wells and boreholes. Geological maps and sections are the final product of the field survey; the scale used for the maps (1:5000) allows evincing single $\sim 20 \mathrm{~m}$-wide outcrops over a $\sim 1$ $\mathrm{km}^{2}$ large area. The geological section shows a tentative reconstruction of the bedrock up to 200-300 m below the site.

At present, we collected geological data regarding about forty existing seismic stations plus a number of sites for future stations. In the following, we show maps and sections of four ITSN sites that are representative of some of the most interesting geological situations observed in the field.

\subsection{Field cases}

Figure 7 shows the results of the survey at the station FVI, Forni Avoltri, in the Eastern Alps. This is an example of a site that satisfies many of the above-mentioned requirements and that exhibits scarce geological and/or geomorphological problems. The good geological quality of this location also reflects into the good quality of the seismic noise recorded at the site (Cucci et al., 1994).

Figure 8 shows a geological section at the site RFI, on the volcanic edifice of Roccamonfina in Central-Southern Italy. Although the choice of this area was mainly forced in order to improve the geometry of the existent network, the field survey allowed us selecting a site with considerable thickness of competent rocks just over the central latite dome.

Moraines are heterogeneous glacial deposits that usually appear chaotic, colluviated and weakly cemented; these poor geotechnical char-
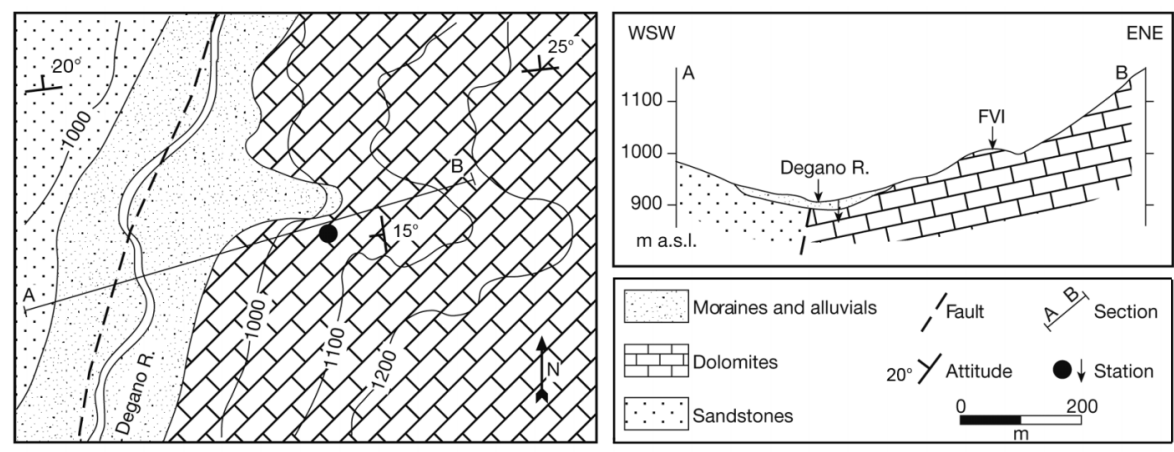

Fig. 7. Geological map and section at the site of the station FVI (Forni Avoltri). Contour topography isobaths is also shown. 

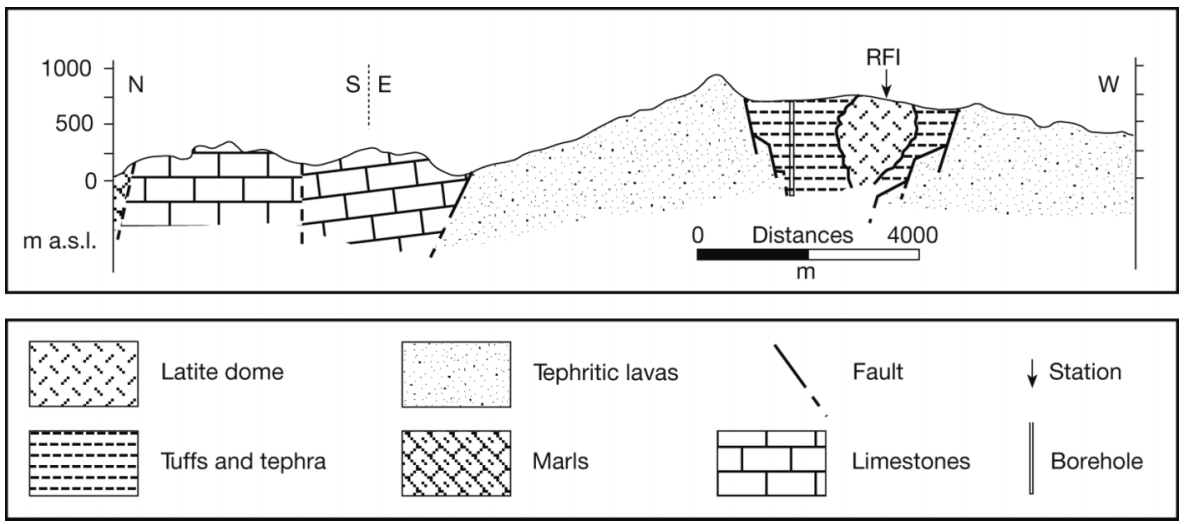

Fig. 8. Geological section at the site of the station RFI (Roccamonfina).
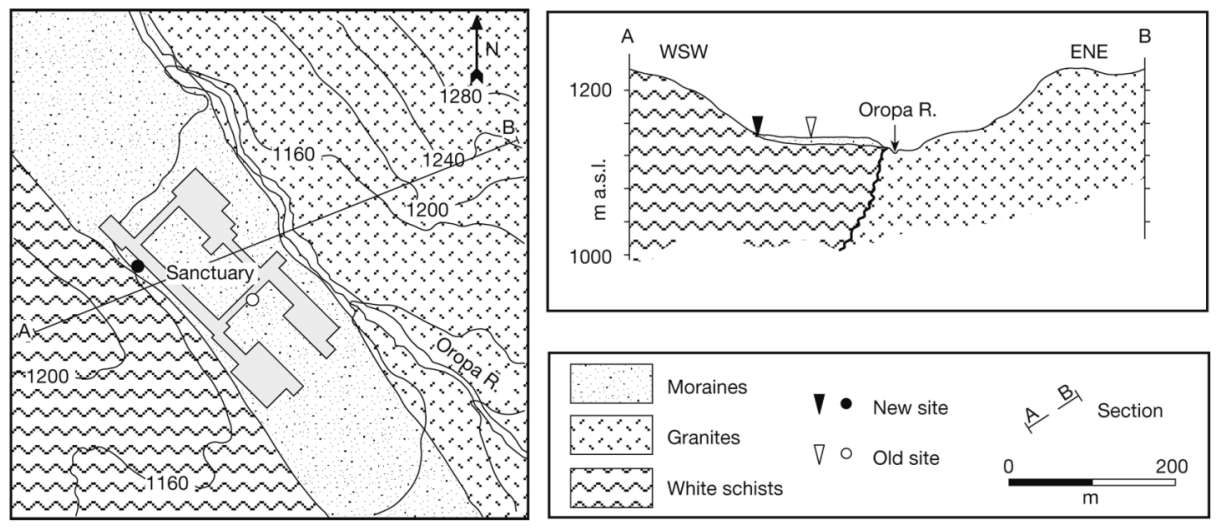

Fig. 9. Geological map and section at the site of the station ORO (Oropa).
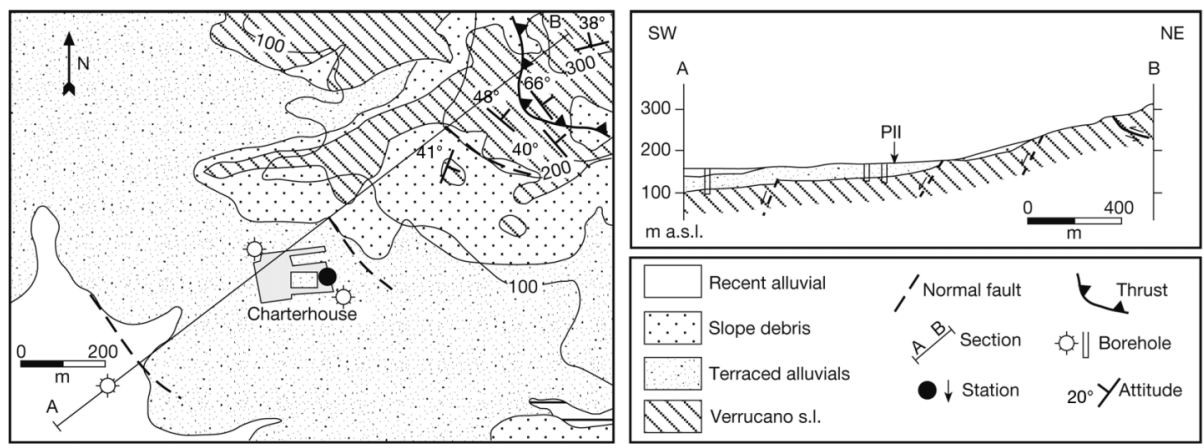

Fig. 10. Geological map and section at the site of the station PII (Pisa). 
acteristics make moraines not very suitable to host seismic stations. At the site ORO (Oropa in the north-western Alps, see fig. 9, station deployed before 1992), 30-40 m-thick Wurm moraines younger than $15 \mathrm{ka}$ are deeply eroded by the adjacent stream and poorly cemented. After the geological field survey, the station was moved to a near site characterized by outcropping bedrock, where the signal-to-noise ratio was significantly better.

The map and section in fig. 10 represent the geological setting at the PII-Pisa station in Central Italy. Here, the stratigraphy of a number of boreholes greatly helped to evaluate the thickness of the alluvial deposits in the area and to choose the most favourable site where we deployed the seismometer. The preferred site exhibits a low level of seismic noise despite the close Arno River, with a peak at $0.7 \mathrm{~Hz}$ (Cimini et al., 1994) possibly indicating site resonance.

\section{From past data to future developments}

In the period from 1 January 2000 to 31 December 2002 (hereinafter 2000-2002) 24458 events have been recorded, $35 \%$ of which have been reliably located (the «gain»). Although the absolute number of recorded events nearly doubled, the «gain» decreased from $44 \%$ in the years 1985-1987 down to $35 \%$ in the years 2000-2002. This change depends on the network only, since all the other parameters are the same. This section investigates the reasons for such earthquake «losses», suggesting actions to improve network gains. Such improvements do not seem out of reach - where not yet undertaken, as nine $(\approx 10 \%)$ stations record more than $50 \%$ of not-localised earthquakes (see table I).

Among the 15627 poorly-located events and sparse readings, we select the 15463 with a reliable $S$ - $P$ reading at the closest station. The dis-

Table I. Median and estimated standard error of $S-P$ delays measured at the closest station for the 15437 notlocated earthquakes that occurred in 2000-2002. «Events no.» is the number of not-located earthquakes, and «cumulate percentage» is relative to the totality of the events.

\begin{tabular}{cccccccc}
\hline \hline No. & $\begin{array}{c}\text { Station } \\
\text { code }\end{array}$ & Lat & Long & $\langle S-P>(\mathrm{s})$ & $\begin{array}{c}\text { Standard } \\
\text { error }(\mathrm{s})\end{array}$ & Events no. & $\begin{array}{c}\text { Cumulate } \\
\text { percentage }\end{array}$ \\
\hline 1 & SFI & 43.904 & 11.847 & 5.20 & 0.17 & 1811 & $11.73 \%$ \\
2 & NRCA & 42.833 & 13.113 & 3.38 & 0.25 & 1671 & $22.56 \%$ \\
3 & USI & 38.710 & 13.180 & 7.92 & 0.18 & 1046 & $29.33 \%$ \\
4 & ASS & 43.062 & 12.652 & 3.47 & 0.23 & 824 & $34.67 \%$ \\
5 & CPI2 & 41.585 & 14.318 & 3.15 & 0.41 & 618 & $38.67 \%$ \\
6 & SNTG & 43.254 & 12.940 & 4.58 & 2.33 & 547 & $42.22 \%$ \\
7 & MNS & 42.384 & 12.680 & 3.69 & 0.40 & 436 & $45.04 \%$ \\
8 & RGNG & 41.674 & 15.586 & 4.35 & 0.42 & 433 & $47.85 \%$ \\
9 & ARV & 43.498 & 12.944 & 3.74 & 2.58 & 392 & $50.39 \%$ \\
10 & MRLC & 40.761 & 15.489 & 2.91 & 0.45 & 385 & $52.88 \%$ \\
11 & CRE & 43.619 & 11.950 & 2.93 & 0.47 & 375 & $55.31 \%$ \\
12 & DOI & 44.503 & 7.245 & 4.92 & 2.88 & 347 & $57.56 \%$ \\
13 & SDI & 41.709 & 13.810 & 2.98 & 0.72 & 343 & $59.78 \%$ \\
14 & PTCC & 46.405 & 13.353 & 4.31 & 0.68 & 283 & $61.61 \%$ \\
15 & GSCL & 44.350 & 10.587 & 3.78 & 0.53 & 262 & $63.31 \%$ \\
16 & SOI & 38.073 & 16.054 & 5.00 & 1.27 & 251 & $64.93 \%$ \\
17 & BRMO & 46.476 & 10.373 & 2.88 & 0.73 & 234 & $66.45 \%$ \\
18 & MNO & 37.933 & 14.694 & 5.67 & 3.01 & 198 & $67.73 \%$ \\
19 & RNI2 & 41.702 & 14.152 & 3.36 & 1.53 & 178 & $68.89 \%$ \\
20 & PTQR & 42.021 & 13.400 & 4.50 & 0.36 & 171 & $69.99 \%$ \\
\hline
\end{tabular}




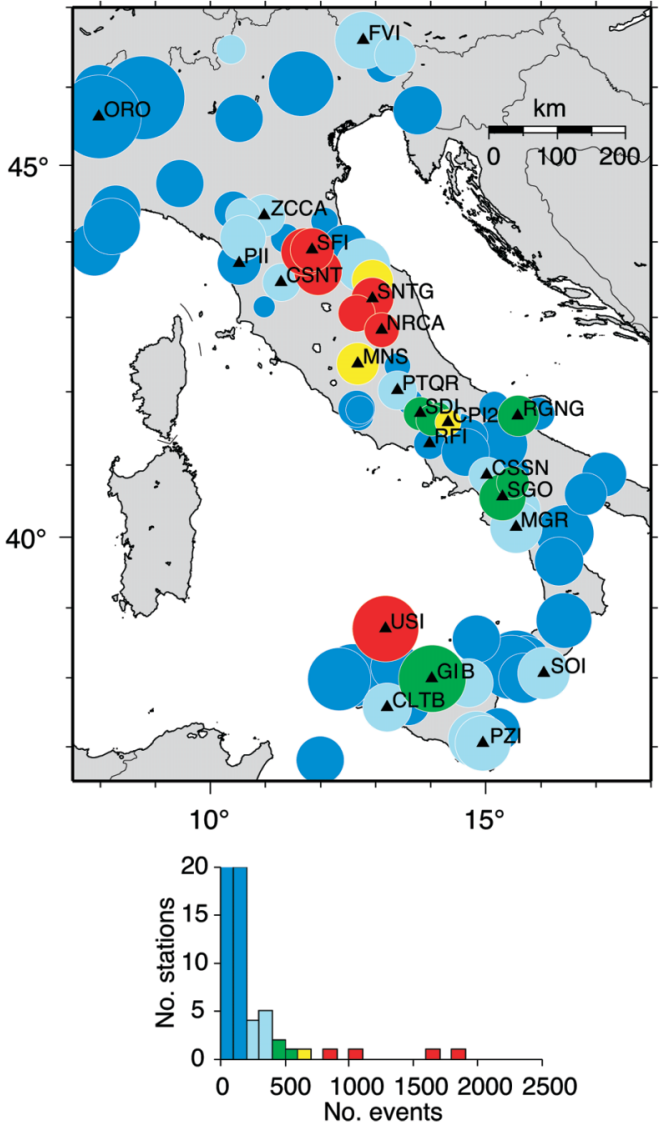

Fig. 11. Average $S-P$ distance and number of nonlocated earthquakes, with the histogram of the no. of stations in bins of 100 events. The circle radius is proportional to the average $S$ - $P$ time $(50 \mathrm{~km}$ radius for $10 \mathrm{~s}$ ), whereas the colour (azure, cyan, green, yellow, red) depends on the number of data at each station. Circles with more events lie higher. The histogram adopts the same colour scheme of the circles, but the vertical scale is cropped at 20 stations for number of events less than 100.

tribution of $S$ - $P$ delay times is positively skewed, and the central $99 \%$ range is $0.73 \mathrm{~s}$ $12.34 \mathrm{~s}$. The median of such distribution is 3.91 $\mathrm{s}$, with an estimated standard error of $2.43 \mathrm{~s}$. For each station, we computed the median of the $S$ - $P$ delays of all the non-located earthquakes recorded at the station; then we converted such median to a distance by multiplying the delay by $6.4 \mathrm{~km} / \mathrm{s}$. This ratio derives from fitting located earthquakes $S-P$ and distance data for short distances only and therefore depends on the shallowest slower crustal layers; it is not to be used for all distances. We represent for each station a circle whose radius is the median distance from the station (fig. 11) and whose colour represents the number of non-located events recorded at the station. We can easily identify the areas that might need actions to improve the network gain (although in some cases the action has already been taken at the time of writing). From fig. 11, we select the following cases (south to north, counter clockwise):

1) In northwestern Sicily, the USI station (red colour in fig. 11) recorded more than 1000 events as the closest station (table I). Such a large number derives from a sequence that occurred $40 \mathrm{~km}$ off-shore Palermo (NW Sicily) in the second half of 2002. Improvements in this case would have come only from off-shore seismometers.

2) In Western (Belice valley) and Central Sicily, despite the good station coverage, a significant number of earthquakes were missed around the CLTB (cyan) and GIB (green) stations. We think that stations currently installed in this area are too noisy. However, the low number of $S$-readings at CLTB might be a starting point for investigating ways to improve the station quality. In Southern Calabria, the station SOI (cyan) seems to indicate a similar problem.

3) In southeastern Sicily, several earthquakes are lost because only three stations exist in the area. Therefore, additional stations close to PZI and MEU (cyan) could add details to the local seismicity. The recently installed station SSY (not shown in the map) might provide the required additional data. However, more help might come from selected stations belonging to the Etna volcano network, located just to the north.

4) In the Southern Apennines, we find cyan and green stations along the Tyrrhenian coast (MRLC, SGO, MGR, SLCN, and CSSN), indicating low efficiency where the network is dense, and several sparse azure stations along the Ionian coast, indicating the presence of local seismicity hard to detail. The former problem might be due to high attenuation in the Tyrrhenian side, whereas the latter to the scarce 
network coverage. Recently (2003), the station density increased in the area, possibly overcoming the latter problem. In the Gargano promontory, the stations RGNG (green) and FGMS record a great number of small earthquakes not well studied yet. Deploying one more station in the surrounding might help studying such microseismicity, given also the good quality of sites in the area.

5) In the Central Apennines, stations CPI2 (yellow), SDI, RNI2, RVI2 (green), and PTQR (cyan) indicate low network efficiency in a region with high station density. The station RFI (azure) constitutes an exception; despite the low number of non-located earthquakes, the high noise level might hinder proper phase reading. A more accurate survey is therefore required to address this issue. More to the north, the high number of non-located earthquakes at MNS (yellow), SNTG, ASS, and NRCA (red) indicate low station coverage. In this area, the station density recently increased.

6) In the Northern Apennines, the large number of missed earthquakes at CSNT (cyan), CRE, SFI, and PGD (red) indicate a poor network density/geometry, especially west of the chain. Increasing the density in that location might solve, at the same time, the geometry problems evidenced by stations BDI, GSCL, ZCCA (cyan). Station PII (azure, fig. 10), despite the low noise level, shows less than average performances. Moving the site to the Verrucano formation (fig. 10) might increase its quality.

7) In the Eastern Alps, the cyan station FVI recorded a certain number of non-located earthquakes occurring at a median distance of about $50 \mathrm{~km}$. The good site quality surely contributes to this good performance. Phase readings obtained by the Friuli local network can definitely improve details of the seismicity in the area. In the Western Alps, especially around ORO station (azure), a certain amount of diffuse seismicity might easily be detailed by increasing the station density. ORO shows how a good quality station (fig. 9) allows recordings with $S$ $P$ reliable readings at significant distances (median distance $\sim 65 \mathrm{~km}$ ). The optimal performance of ORO was achieved thanks to the joint geological-seismological survey aimed at improving the signal-to-noise ratio.

\section{Conclusions}

We analysed performances of the Italian seismic network in the years 1985-2002, i.e., we defined basic significant parameters whose evolution in time might indicate quality of the earthquake locations. Then we verified the gain of the network, defined as the percentage of located earthquakes with respect to the recorded earthquakes, and suggested possible actions to take in order to increase the gain.

Completeness magnitude can be as low as 2.2 when we consider non-located earthquakes, whereas the completeness for located earthquakes is 2.4 in the average, over the analysed period. When the location reliability is not the prime concern, the non-located earthquakes can be used in specific studies, for example to analyse dependence of the $b$-value on time.

The average distance between earthquakes and the closest station decreases of $\sim 6 \mathrm{~km}(\sim 20 \%)$ or even of $\sim 15 \mathrm{~km}$ in specific areas. Such variations are real, i.e. they are measured over real earthquakes in real operating conditions, and not speculative. Therefore, these numbers do not account for density improvement brought forth in areas after a seismic sequence.

RMS of the location decreases regularly with time, for both lower and higher magnitude events, from $0.5 \mathrm{~s}$ to $0.4 \mathrm{~s}$, and from $0.7 \mathrm{~s}$ to 0.6 $\mathrm{s}$ respectively (fig. 5). These values do not account for improvements in the velocity model obtained during the past years, as we made calculations using only one laterally homogeneous model. Therefore, the RMS reduction reflects network changes only.

Methods for geologic and seismological characterisation of a possible station site also proved to be effective. We relate the good performances of ORO station to the good site quality achieved after a joint geological and seismological survey.

Finally, we represented the number of missed earthquakes at each station. We showed that nine stations control more that $50 \%$ of all missed earthquakes, and suggested areas in Italy where the network might be easily improved. The low gain is apparently due to insufficient coverage in some cases and to station or site quality in others. 


\section{Acknowledgements}

Many thanks to Francesco Mele and Bruce Presgrave for the accurate reviews. A discussion with FM leaded to the relative-RMS idea. Computer programs initially written by $\mathrm{A}$. Basili and G. Smriglio were modified to fit the purpose of this work. Some figures were drawn with GMT (Wessel and Smith, 1991).

\section{REFERENCES}

BADIALI, L. and F. MELE (2000): Elaborazione simultanea di segnali digitali e analogici della Rete Sismica Nazionale Centralizzata in ambiente distribuito client/server, Quad. Geofis., 3 (INGV, Roma).

Barba, S., R. Di Giovambattista and G. Smriglio (1995a): Accessing the Istituto Nazionale di Geofisica Seismic Network Databank (ISDN), Eos, Trans. Am. Geophys. Un., 76, p. 89.

Barba, S., R. Di Giovambattista and G. Smriglio (1995b): The ING Seismic Network Databank (ISND): a friendly parameters and waveform database, Ann. Geofis., XXXVIII (2), 213-219.

Boschi, E., A. Basili, R. Console, F. Mele and G. SmRIGLIO (1990): Seismological analysis with automatic processing for the Italian telemetered network, Publication ING No. 518, Roma.

Cattaneo, M., P. Augliera and M. Demartin (2002): Seismic noise measuraments for the Italian national seismic network, in XXVIII General Assembly of the European Seismological Commission (ESC), 1-6 September 2002, Genova (Italy), p. 267 (abstract).

Cimini, G.B., L. CuCCI, M. Pirro and A. NARdi (1994): Studio delle caratteristiche geologico-geofisiche dei siti di stazione della Rete Sismica Nazionale Centralizzata: le stazioni di Pisa, Bagni di Lucca, Bobbio, S. Marino e Barisano, Pubblicazione ING No. 560, pp. 28.

CuCCI, L. and M. PIrRo (1992): Il rilevamento geologico dei siti di stazione della rete sismica nazionale centralizzata, Pubblicazione ING No. 541, pp. 27.

Cucci, L. and M. PIRro (1993): La geologia di 8 siti di stazione della RSNC, Pubblicazione ING No. 552, pp. 53.

Cucci, L., G.B. Cimini, M. Pirro and A. NArdi (1994): Caratterizzazione geologico-geofisica dei siti di stazione della RSNC, in Atti del $12^{\circ}$ Convegno GNGTS, vol. 1, 483-488.

De Simoni, B. (1987): L'attuale Rete Sismica Nazionale Centralizzata (RSNC) dell'Istituto Nazionale di Geofisica: futuri sviluppi (In Italian), in Aree Sismogenetiche e Rischio Sismico in Italia, edited by E. BoschI and M. Dragoni (Ed. Galileo Galileo, Lausanne), vol. I.

Di Giovambattista, R. and S. Barba (1997): An estimate of hypocenter location accuracy in large networks: possible implications for tectonic studies in the Italian case, Geophys. J. Int., 129, 124-132.

Di MARo, R. and A. Marchetti (1992): La rete sismica del Sannio-Matese, Pubblication ING No. 540.

Havskov, J., P. BoRMANN and J. SCHWEITZER (2002): IS 11.1: Earthquake location, in IASPEI New Manual of Seismological Observatory Practice, edited by P. BORMANN (GeoForschungsZentrum Potsdam), vol. 2, pp. 28.

TAccetti, Q. and F. Mele (1989): Un sistema automatico d'analisi ed archiviazione di dati sismici, in Dieci Anni di Attività (1980-1989), edited by E. BosCHI, R. CoNSOLE and A. Meloni (Ed. Il Cigno Galileo Galilei).

VAlensise, G. and D. PANTosti (Editors) (2001): Database of potential sources for earthquakes larger than $M 5.5$ in Italy, Ann. Geofis., 44 (suppl. to no. 4), pp. 180 (with CD-ROM).

Wessel, P. and W.H.F. SMith (1991): Free software helps map and display data, Trans. Am. Geophys. Un., 72, p. 441. 